\title{
PHYSICAL PROPERTIES OF HIGH TEMPERATURE SUPERCONDUCTORS I
}


This page is intentionally left blank 


\section{PHYSICAL PROPERTIES OF}

\section{HIGH TEMPERATURE}

\section{SUPERCONDUCTORS I}

Editor

Donald M. Ginsberg

Professor of Physics

University of Illinois at Urbana-Champaign 
Published by

World Scientific Publishing Co. Pte. Ltd.

P O Box 128, Farrer Road, Singapore 9128

USA office: World Scientific Publishing Co., Inc.

687 Hartwell Street, Teaneck, NJ 07666, USA

UK office: World Scientific Publishing Co. Pte. Ltd.

73 Lynton Mead, Totteridge, London N20 8DH, England

\begin{abstract}
PHYSICAL PROPERTIES OF HIGH TEMPERATURE SUPERCONDUCTORS I
Copyright $\odot 1989$ by World Scientific Publishing Co. Pte. Ltd.

All rights reserved. This book, or parts thereof, may not be reproduced in any form or by any means, electronic or mechanical, including photocopying, recording or any information storage and retrieval system now known or to be invented, without written permission from the Publisher.
\end{abstract}

ISBN $9971-50-683-1$

9971-50-894-X (pbk)

Printed in Singapore by Utopia Press. 
This book is dedicated to the many scientists and students who bave risen to the bigh $T_{c}$ challenge. 
This page is intentionally left blank 


\section{PREFACE}

The discovery in 1986 of high temperature superconductivity has produced a flood of experimental and theoretical publications, approximately 10,000 of them. This book maps out some of the main currents in an ocean of papers. We concentrate on the experimentally determined physical properties of these materials, and compare these properties with the predictions of theoretical models.

It was not easy to choose the topics for this book, which is necessarily limited in size. Chapters which would have been desirable include nuclear magnetic and quadrupole resonance, magnetic ordering, microstructure, electron tunneling, photoemission, and thermoelectric properties in the mixed state. We expect this book to be the first in a series of volumes to be published by World Scientific on the physical properties of high temperature superconductors. Later volumes will incorporate some of the missing subjects, as well as further developments in some of the topics which are covered here.

The authors of this book have made a significant sacrifice, taking time from their own research during a period of very great activity. They have done a job which is extremely difficult because of the deluge of preprints and articles. There is no way the authors could be aware of all the worthy manuscripts which have been written, and certainly it has been impossible for them to include references to all the literature in the field. Indeed, only by leaving out a great deal could they give each chapter a form which can be readily grasped. We ask you, the reader, to be understanding of these problems if you discover that some of your own work has gone unmentioned.

Donald M. Ginsberg

Urbana, Illinois

Nov. 1, 1988 
This page is intentionally left blank 


\section{CONTENTS}

Preface vii

Chapter 1: Introduction, History, and Overview of High 1 Temperature Superconductivity D.M. Ginsberg

Chapter 2: Thermodynamic Properties, Fluctuations, and

Anisotropy of High Temperature Superconductors

M.B. Salamon

Chapter 3: Macroscopic Magnetic Properties of High Temperature Superconductors A.P. Malozemoff

Chapter 4: Neutron Scattering Studies of Structural and Magnetic Excitations in Lamellar Copper Oxides - A Review R.J. Birgeneau and G. Shirane

Chapter 5: Normal State Transport and Elastic Properties of High $T_{\mathrm{c}}$ Materials and Related Compounds P.B. Allen, Z. Fisk, and A. Migliori

Chapter 6: Rare Earth and Other Substitutions in High

Temperature Oxide Superconductors

J.T. Markert, Y. Dalichaouch, and M.B. Maple

Chapter 7: Infrared Properties of High $T_{\mathrm{c}}$ Superconductors

T. Timusk and D.B. Tanner

Chapter 8: Raman Scattering in High- $T_{c}$ Superconductors

C. Thomsen and M. Cardona 